\title{
Hexavalent Chromium Removal from Model Water and Car Shock Absorber Factory Effluent by Nanofiltration and Reverse Osmosis Membrane
}

\author{
Amine Mnif, Imen Bejaoui, Meral Mouelhi, and Béchir Hamrouni \\ Desalination and Water Treatment Research Unit, Faculty of Sciences of Tunis, University of Tunis El Manar, \\ El Manar II, 2092 Tunis, Tunisia \\ Correspondence should be addressed to Amine Mnif; amine.mnif@gmail.com
}

Received 21 March 2017; Revised 18 May 2017; Accepted 14 June 2017; Published 27 July 2017

Academic Editor: Adil Denizli

Copyright (C) 2017 Amine Mnif et al. This is an open access article distributed under the Creative Commons Attribution License, which permits unrestricted use, distribution, and reproduction in any medium, provided the original work is properly cited.

\begin{abstract}
Nanofiltration and reverse osmosis are investigated as a possible alternative to the conventional methods of Cr(VI) removal from model water and industrial effluent. The influences of feed concentration, water recovery, $\mathrm{pH}$, and the coexisting anions were studied. The results have shown that retention rates of hexavalent chromium can reach $99.7 \%$ using nanofiltration membrane (NF-HL) and vary from 85 to $99.9 \%$ using reverse osmosis membrane (RO-SG) depending upon the composition of the solution and operating conditions. This work was also extended to investigate the separation of $\mathrm{Cr}(\mathrm{VI})$ from car shock absorber factory effluent. The use of these membranes is very promising for $\mathrm{Cr}(\mathrm{VI})$ water treatment and desalting industry effluent. Spiegler-Kedem model was applied to experimental results in the aim to determine phenomenological parameters, the reflection coefficient of the membrane $(\sigma)$, and the solute permeability coefficient $\left(P_{s}\right)$. The convective and diffusive parts of the mass transfer were quantified with predominance of the diffusive contribution.
\end{abstract}

\section{Introduction}

The rapid industrialization and development in industrial processes led to the presence of heavy metals in water and industrial effluents. These components are extremely toxic and are released in huge quantities by several industries. Among these constituents, one can mention the chromium compounds that exist in several oxidation states as trivalent chromium (Cr(III)) and hexavalent chromium (Cr(VI)).

$\mathrm{Cr}(\mathrm{III})$ is considered as an essential trace nutrient for humans with an established adequate daily dietary intake range for adults from 20 to $35 \mu \mathrm{g}$ chromium [1]. However, high concentration of this element is extremely toxic, teratogenic, and mutagenic presenting a great threat to human beings when ingested through the respiratory and digestive tract or through skin contact $[2,3]$. In addition, $\mathrm{Cr}(\mathrm{VI})$ is included in the list of the US Environmental Protection Agency for prioritizing control of its application. According to the World Health Organization standards, the maximum level for chromium is $0.05 \mathrm{mg} \mathrm{L}^{-1}$ for hexavalent chromium and $0.1 \mathrm{mg} \mathrm{L}^{-1}$ for total chromium in drinking water $[4,5]$.
Chromium is extensively used in tanning operation to obtain leather of desirable quality. It is also used in the production of pigments, the manufacture of stainless steel, and electroplating and as a biocide in the cooling waters of nuclear power plants [6].

Among the nine valence states of chromium ranging from -2 to +6 , only hexavalent and trivalent chromium have primary environmental significance due to their stable oxidation forms in the environment [7]. Depending on the $\mathrm{pH}$ of the solution, $\mathrm{Cr}(\mathrm{VI})$ typically exists in two forms, chromate $\left(\mathrm{CrO}_{4}{ }^{2-}\right)$ and dichromate $\left(\mathrm{Cr}_{2} \mathrm{O}_{7}{ }^{2-}\right)$ [8]. These two divalent oxyanions are very water soluble and poorly adsorbed by soil and organic matter, making them mobile in soil and groundwater [9].

Therefore, in order to sustain our global water supply, analytical methods for the removal of $\mathrm{Cr}(\mathrm{VI})$ were developed such as chemical reduction, precipitation, evaporation, and ion exchange [10-12]. Although ion exchange resins can substantially remove metal ions, they do not show mechanical strength because of swelling of polymeric skeleton and low selectivity. Precipitation is high cost process and treated water 
TABLE 1: Specifications of NF-HL-2514 and RO-SG-2514 membranes.

\begin{tabular}{lcc}
\hline Membrane reference & NF-HL-2514 & RO-SG-2514 \\
\hline Membrane type & Polyamide thin film composite & Polyamide thin film composite \\
Maximum operating temperature & $50^{\circ} \mathrm{C}$ & $50^{\circ} \mathrm{C}$ \\
Maximum operating pressure & $40 \mathrm{bar}$ & $41 \mathrm{bar}$ \\
Continuous operating pH range & $4-11$ & $2-11$ \\
Membrane area & $0.6 \mathrm{~m}^{2}$ & $0.6 \mathrm{~m}^{2}$ \\
Pure water permeability & $9 \mathrm{~L} \mathrm{~h}^{-1} \mathrm{~m}^{-2} \mathrm{bar}^{-1}$ & $3.85 \mathrm{~L} \mathrm{~h}^{-1} \mathrm{~m}^{-2} \mathrm{bar}^{-1}$ \\
MWCO & $314 \mathrm{Da}$ & $172 \mathrm{Da}^{2}$ \\
\hline
\end{tabular}

still has high chromium ion concentrations. These traditional methods have certain drawbacks and considerable attention has been focused upon absorption and membrane separation $[13,14]$.

Membrane separation has become increasingly attractive for treatment and recovery of heavy metals due to its high efficiency, ease of operating, and low cost $[15,16]$.

In this study, we report the behavior and efficiency of reverse osmosis and nanofiltration on the removal of $\mathrm{Cr}(\mathrm{VI})$ under different water quality conditions, such as $\mathrm{pH}$, ionic strength, and the presence of different competing elements. This work was also extended to investigate the separation of $\mathrm{Cr}(\mathrm{VI})$ from car shock absorber factory effluent in order to meet the environmental local limits $\left(<5 \mathrm{mg} \mathrm{L}^{-1}\right)$ before discharging into the municipal treatment plant. The model of Spiegler-Kedem was then applied to determine the phenomenological and mass transfer parameters.

\section{Materials and Methods}

The present work was performed on a pilot plant equipped with commercial spiral wound reverse osmosis membrane RO-SG-2514 and nanofiltration membrane NF-HL-2514 supplied by Osmonics. Both modules used for this study are approximately $64 \mathrm{~mm}$ in diameter and $356 \mathrm{~mm}$ in length.

Figure 1 shows the schematic diagram of the experimental set-up used in this study. Permeate and retentate water was recycled to the feed tank in order to keep the concentration of the feed solution stable.

The specifications of the membranes in the pilot scale system are described in Table 1.

Before all experiments, the membranes were cleaned and rinsed with ultrapure water $\left(0.05 \mu \mathrm{S} \mathrm{cm}^{-1}\right)$ at $P=5$ bar for at least 30 minutes. The permeate flux $J_{v}$ was determined by measuring the volume of permeate collected in a given time interval per unit membrane area. Observed rejection was calculated by

$$
R=\left(1-\frac{C_{p}}{C_{0}}\right) \cdot 100,
$$

where $C_{p}$ and $C_{0}$ are permeate and feed concentrations, respectively.

The conversion rate $Y$ is given as

$$
Y=\left(\frac{Q_{p}}{Q_{0}}\right) \cdot 100,
$$

where $Q_{0}$ and $Q_{p}$ are the initial and permeate flow rates, respectively.

The phenomenological parameters (salt permeability $(P s)$ and reflection coefficient $(\sigma))$ were determined using the model of Kedem-Katchalsky [17].

$\mathrm{NaCl}$ (99.5\%, Sigma Aldrich), $\mathrm{CaCl}_{2}$ (99.8\%, PROLABO), and $\mathrm{Na}_{2} \mathrm{SO}_{4}(99.0 \%$, ACROS) concentrations and wastewater salinity were measured by conductivity. Concentration of $\mathrm{Cr}(\mathrm{VI})$ in the permeate was determined using a UV-Vis spectrophotometer (TOMOS V-1100) at $540 \mathrm{~nm}$ wave length with 1,5-diphenylcarbazide as a color complexing agent [18]. The adjustment of $\mathrm{pH}$ was made using $\mathrm{NaOH}$ and $\mathrm{HCl}$. All the chemicals used in this study were of analytical grade from Merck. The chromium solutions were prepared using distilled water.

To evaluate the charge of the two membranes, salt retention measurements with $\mathrm{CaCl}_{2}, \mathrm{NaCl}$, and $\mathrm{Na}_{2} \mathrm{SO}_{4}$ $\left(10^{-3} \mathrm{~mol} \mathrm{~L}^{-1}\right)$ as a function of permeate flux give the following retention sequence: $R_{\mathrm{Na}_{2} \mathrm{SO}_{4}}>R_{\mathrm{CaCl}_{2}}>R_{\mathrm{NaCl}}$, which is caused by differences in diffusion coefficients between the different salts for both membranes [19]. However, previous works showed a negatively charged character of both membrane surfaces $[20,21]$.

\section{Results and Discussion}

\subsection{Retention of Hexavalent Chromium Ions from Model Water}

3.1.1. Effect of Conversion Rates on Hexavalent Chromium Retention. The retention rate of $\mathrm{Cr}(\mathrm{VI})$ was studied as a function of conversion rate. An increase in the conversion rate caused a decrease in the retention rate under the same pressure (Figure 2); this could be the result of the decrease in cross flow velocity and the appearance of polarization layer with high conversion rates [22-24].

3.1.2. Effect of Initial Concentration and $\mathrm{pH}$ on the Retention Rate of Hexavalent Chromium. The experiments were carried out on solutions of $\mathrm{K}_{2} \mathrm{Cr}_{2} \mathrm{O}_{7}$ with concentration ranging between 10 and $1000 \mathrm{mg} \mathrm{L}^{-1}$ at various $\mathrm{pH}$ for a fixed transmembrane pressure of 7 bar for NF-HL and RO-SG (Figure 3).

The retention rate of the $\mathrm{Cr}(\mathrm{VI})$ changed according to the variation of feed $\mathrm{pH}$ as well as concentration, but each membrane shows a particular behavior. 


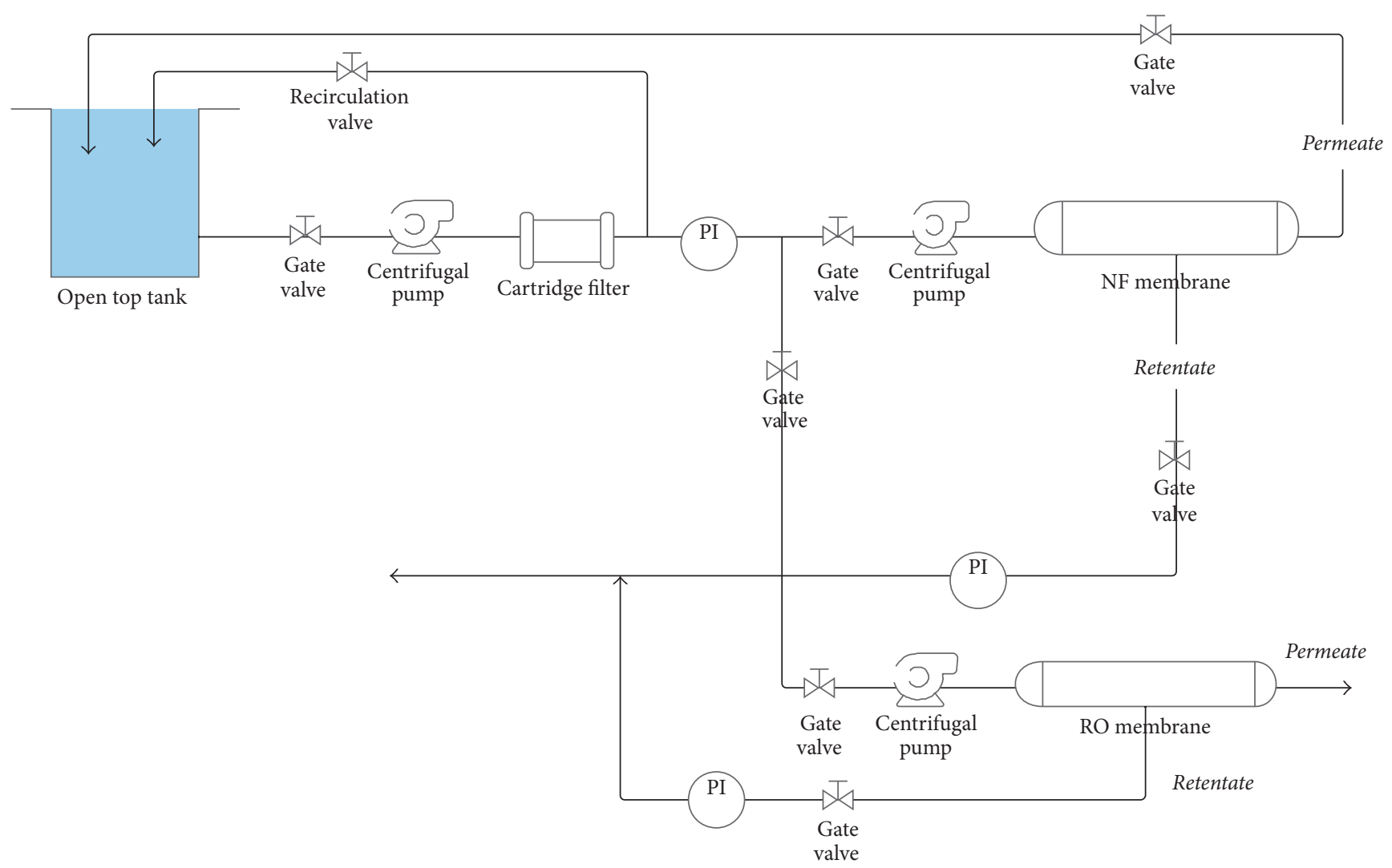

FIGURE 1: Schematic diagram of test system.

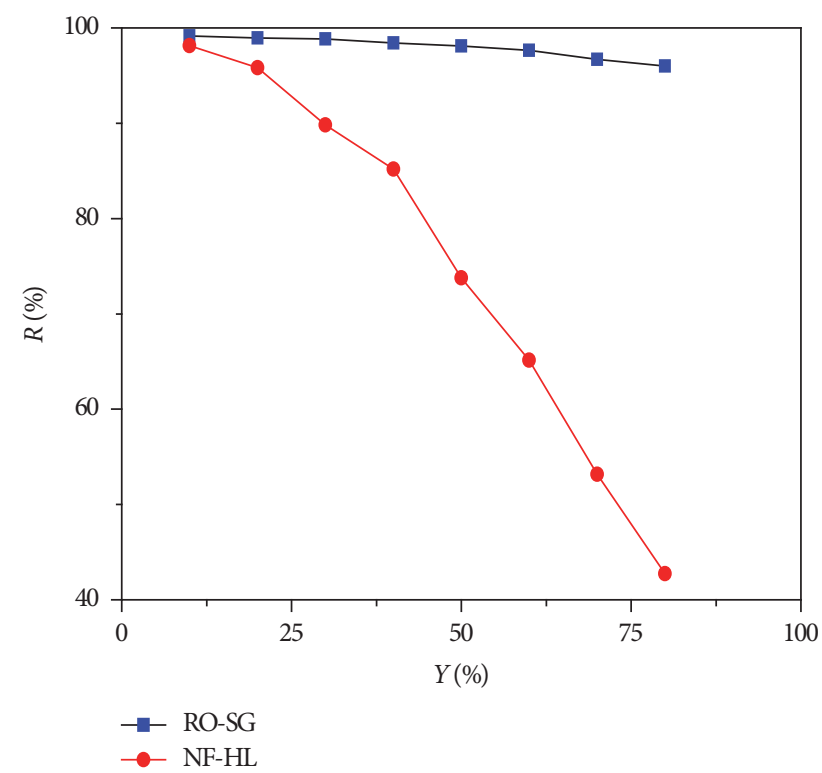

FIGURE 2: Retention rates of hexavalent chromium as a function of conversion rate $\left(\Delta P=6\right.$ bar, $C_{\mathrm{Cr}(\mathrm{VI})}=11 \mathrm{mg} \mathrm{L}^{-1}, \mathrm{pH}=8$, and $\theta=$ $\left.25^{\circ} \mathrm{C}\right)$.

Thus, in the acidic range, more retention rate was observed at lower initial chromium concentration compared to higher concentration for NF-HL membrane (30 to $20 \%$ at $\mathrm{pH} 5$ ), but passing to alkaline range, a reverse trend was observed, where higher retention rate occurred at higher concentrations ( 80.0 to $99.7 \%$ at $\mathrm{pH}$ 8) which can be explained by the dielectric exclusion effect [20]. In fact, $\mathrm{Cr}(\mathrm{VI})$ can exist in the aqueous solution in different ionic forms $\left(\mathrm{HCrO}_{4}^{-}, \mathrm{CrO}_{4}{ }^{2-}, \mathrm{Cr}_{2} \mathrm{O}_{7}{ }^{2-}\right)$, which depend on $\mathrm{Cr}(\mathrm{VI})$ concentration and solution $\mathrm{pH}[25,26]$. According to these results, one can conclude that, in the $\mathrm{pH}$ range 4-5.5, the possible form of $\mathrm{Cr}(\mathrm{VI})$ according to the concentrations is $\mathrm{HCrO}_{4}^{-}$, and in the $\mathrm{pH}$ range of 5.5-11, the various possible forms are $\mathrm{HCrO}_{4}{ }^{-}$until $\mathrm{pH} 6.5$ and $\mathrm{CrO}_{4}{ }^{2-}$ until $\mathrm{pH}$ 11. Therefore, the decrease of the retention rate of $\mathrm{Cr}(\mathrm{VI})$ between $\mathrm{pH} 4$ and 5.5 cannot be explained by a change in chromium form but is presumably due to the screening effect caused by the presence of the negative charge on the NF-HL membrane surface [17]. Passing from pH 5.5 to 11, the increase of retention rate with concentration could be explained by the dielectric exclusion effect besides the change in chromium forms due to the changes in the relative amount of monovalent $\left(\mathrm{HCrO}_{4}{ }^{-}\right)$and divalent ions $\left(\mathrm{CrO}_{4}{ }^{2-}\right)$ present in solution. This can explain the higher retention at high concentration in the studied $\mathrm{pH}$ range when dissociation to bivalent ions is more extensive.

Whereas the retention rate of $\mathrm{Cr}(\mathrm{VI})$ decreased all over the range of $\mathrm{pH}$ when increasing concentration for RO-SG membrane ( 99.9 to $97.0 \%$ at $\mathrm{pH} 8$ ), this can be explained by the screening effect involved by the increase in the concentration of potassium cations in the solution [27]. At high salt concentration $\left(\mathrm{K}_{2} \mathrm{Cr}_{2} \mathrm{O}_{7}\right)$, the negative charge 

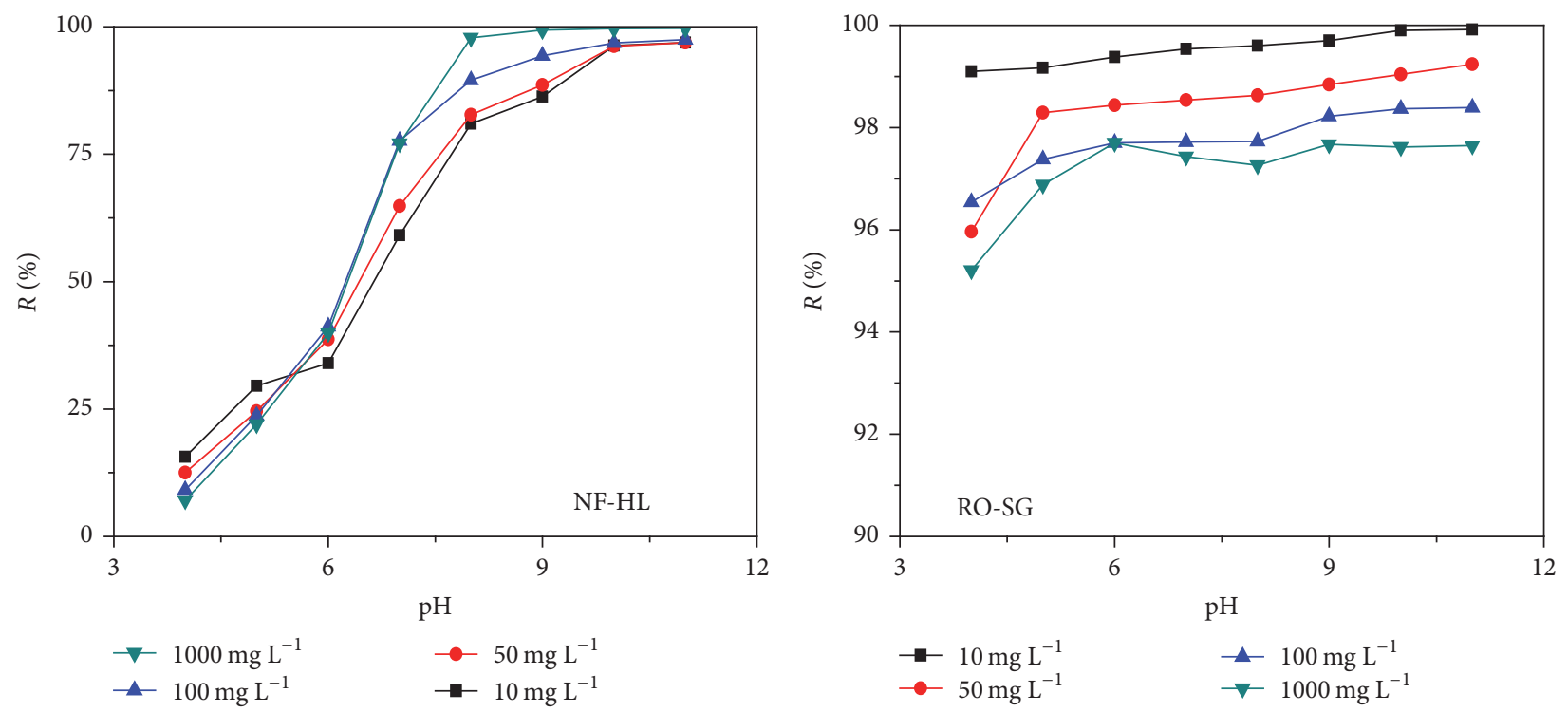

FIGURE 3: Evolution of retention rate of $\mathrm{Cr}(\mathrm{VI})$ as a function of initial feed concentration at different $\mathrm{pH}$.

of the membrane was gradually neutralized by potassium cations and therefore a decrease in the electrostatic repulsions (between the anions in solution and the negative charges of the membrane) facilitated the transfer of $\mathrm{HCrO}_{4}{ }^{-}$or $\mathrm{CrO}_{4}{ }^{2-}$ ions through the membrane.

An increase in retention rate of $\mathrm{Cr}(\mathrm{VI})$ with increasing $\mathrm{pH}$ values for each concentration was observed for both membranes. In fact, in a pH below 6.5, monovalent species $\mathrm{HCrO}_{4}{ }^{-}$were dominant, but when $\mathrm{pH}$ was higher than 6.5, divalent species $\mathrm{CrO}_{4}{ }^{2-}$ were dominant.

For $\mathrm{pH}$ ranging from 4 to 6.5 , almost all the chromium species passed through the membrane. When the $\mathrm{pH}$ was adjusted to 6.5 , the permeate concentration of $\mathrm{HCrO}_{4}{ }^{-}$ became lower due to the fact that $50 \%$ of the ions were converted to $\mathrm{CrO}_{4}{ }^{2-}$ when $\mathrm{pH}=\mathrm{pKa}$. When the $\mathrm{pH}$ was adjusted from 8 to 11 , nearly complete removal was achieved, resulting from all the chromium species becoming $\mathrm{CrO}_{4}{ }^{2-}$. This behavior is also in a good agreement with the literature $[26,28,29]$.

3.1.3. Effects of Coexisting Ions. Since real solutions contain different types of ions at different concentrations, possible interaction with the surface of membranes may affect the removal efficiency of $\mathrm{Cr}(\mathrm{VI})$. The correlations between the $\mathrm{Cr}(\mathrm{VI})$ removal and the coexisting ions simulated for different ionic strength in feed water were investigated.

The effect of different competitive ions such as chloride, nitrate, and sulfate on the retention rate of $\mathrm{Cr}(\mathrm{VI})$ was studied at various concentrations for both membranes (Figure 4).

The results show that the retention rate of $\mathrm{Cr}(\mathrm{VI})$ decreased with increasing salt concentrations since the electrostatic effects of the membrane become weaker as $\mathrm{KCl}$, $\mathrm{KNO}_{3}$, or $\mathrm{K}_{2} \mathrm{SO}_{4}$ concentration increases. This is known as the screening phenomenon, where potassium ions neutralize partially the negative charges of the membrane, which involves the decrease of the retention of charged ions, thus facilitating the passage of the hexavalent chromium ions [26]. This was later reported by Hafiane et al. [28]. They mentioned that this can be related to the dependence of the effective charge density $(\Phi X)$ of the membrane on the electrolyte concentrations. Wang et al. [32] proposed the following empirical equation (3) explaining this effect in the case of one electrolyte 1-1:

$$
\Phi X=\frac{A c^{0.5}}{1+B c^{0.5}} .
$$

$A$ and $B$ are empiric constants that depend on the electrolyte and the nature of the membrane. This equation suggests that the density charge of the membrane reached a maximum at elevated salt concentration.

Using NF-HL membrane, the retention rate of $\mathrm{Cr}(\mathrm{VI})$ decreased from 91.4 to $86 \%$ in the presence of $\mathrm{KCl}$ and $\mathrm{KNO}_{3}$ and down to $74.9 \%$ by adding $\mathrm{K}_{2} \mathrm{SO}_{4}$, while it decreased from 98.6 to $90.2,93.3$, and $85.4 \%$ in the presence of $\mathrm{KCl}, \mathrm{KNO}_{3}$, and $\mathrm{K}_{2} \mathrm{SO}_{4}$, respectively, in the case of RO-SG.

In presence of bivalent ions $\left(\mathrm{SO}_{4}{ }^{2-}\right)$, the reduction in the retention rate of $\mathrm{Cr}(\mathrm{VI})$ was more pronounced than in presence of monovalent ions $\left(\mathrm{Cl}^{-}, \mathrm{NO}_{3}{ }^{-}\right)$. This may be explained by the exclusion phenomenon attributed to the different valence of the coion.

In order to better understand the transport phenomenon, the experimental data of retention and flux for all investigated salts were fitted using the Spiegler-Kedem model to determine the salt permeability $\left(P_{s}\right)$ and reflection coefficient $(\sigma)$ parameters as well as the diffusive and convective contributions (Figures 5 and 6).

As illustrated in Figures 5 and 6, the analysis of $\mathrm{Cr}(\mathrm{VI})$ concentration $\left(C_{p}\right)$ in the permeate in presence of $\mathrm{KCl}$ as a function of the reverse permeate flux $\left(1 / J_{v}\right)$ revealed a linear relation in conformity with the Spiegler-Kedem model. The two membranes imply two different mechanisms of transfer of aqueous solution, 

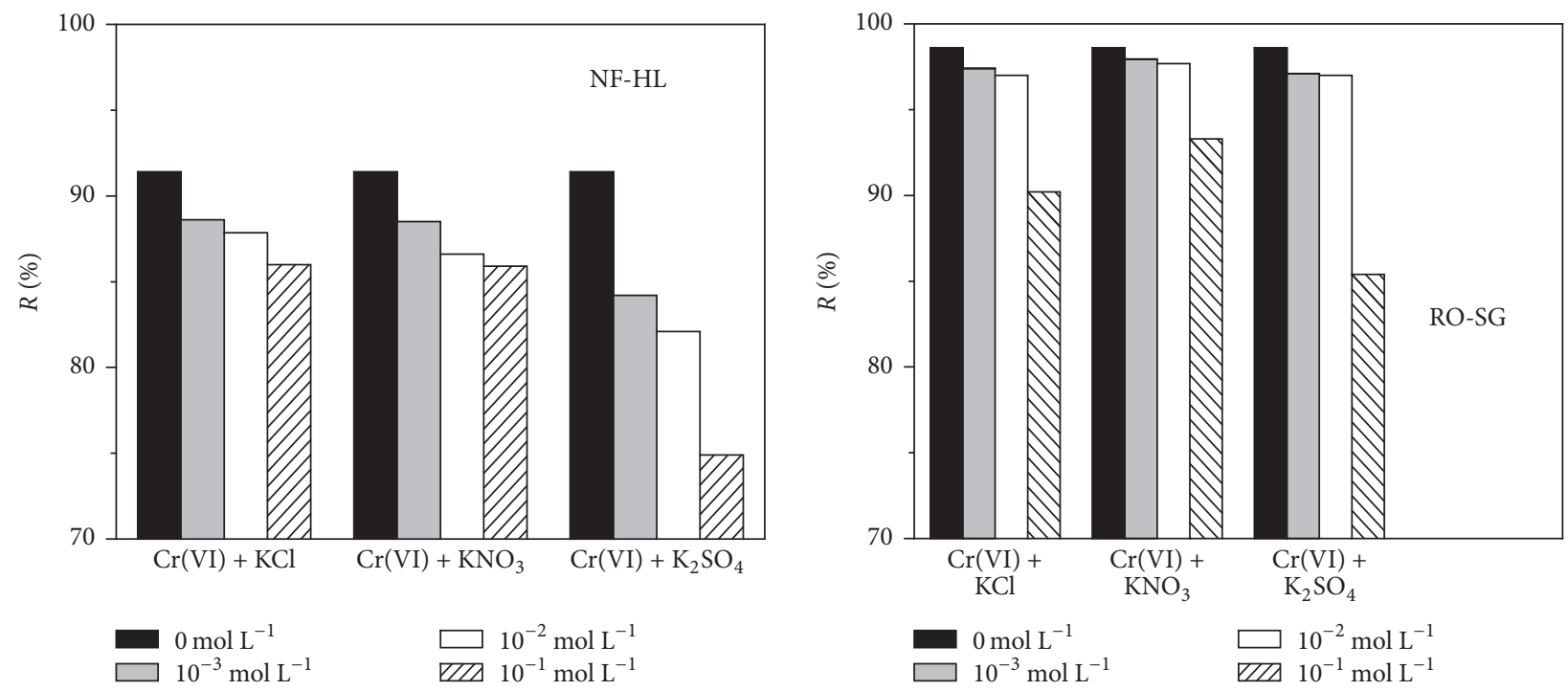

FIGURE 4: Effect of the ionic strength and coexisting ions on the retention rate of $\mathrm{Cr}(\mathrm{VI})\left(C_{\mathrm{Cr}(\mathrm{VI})}=50 \mathrm{mg} \mathrm{L} \mathrm{L}^{-1}, Y=50 \%, \Delta P=6\right.$ bars, $\mathrm{pH}=8$, and $\theta=25^{\circ} \mathrm{C}$ ).
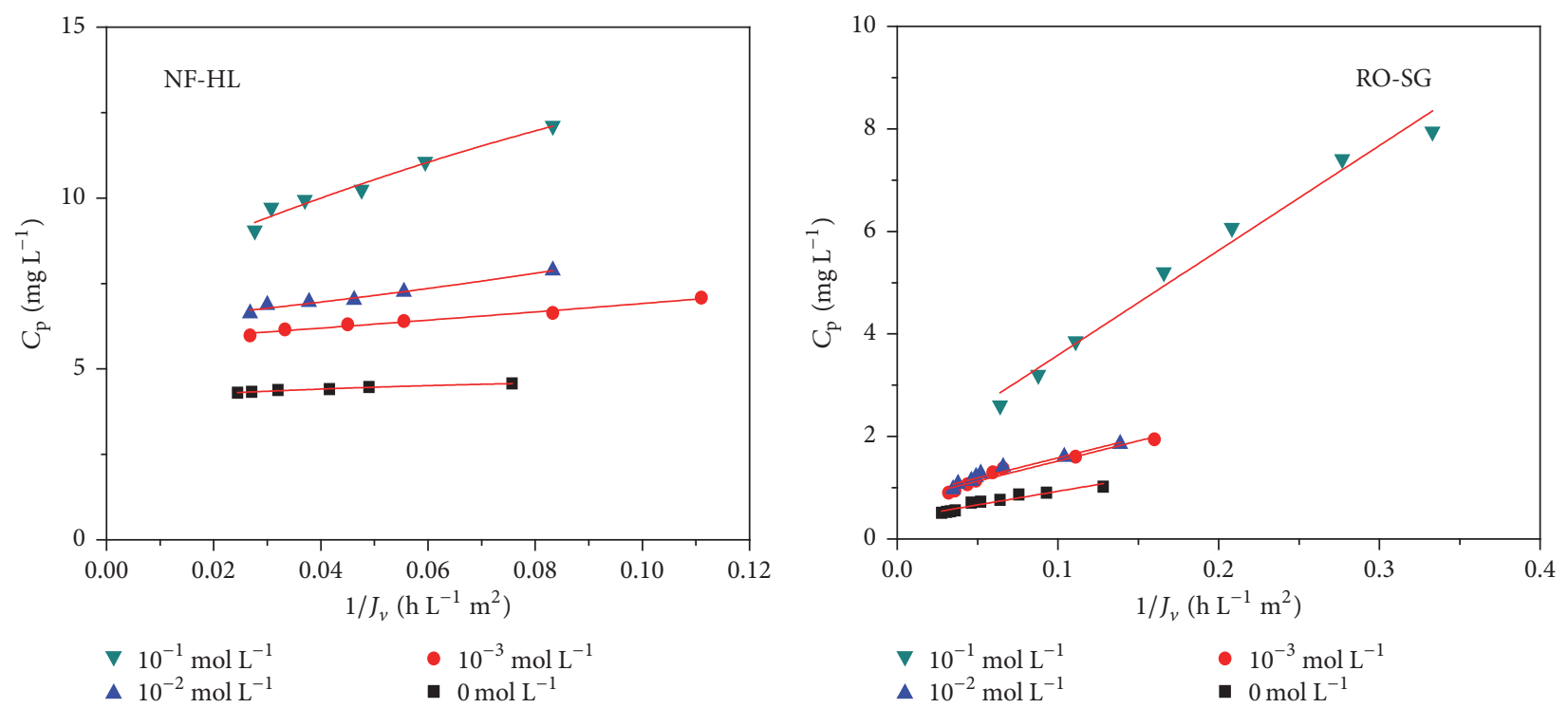

FIGURE 5: Variation of the permeate concentration in function of $1 / J_{v}$ of $\mathrm{Cr}(\mathrm{VI})$ at different $\mathrm{KCl}$ concentrations $\left(C_{\mathrm{Cr}(\mathrm{VI})}=50 \mathrm{mg} \mathrm{L} \mathrm{L}^{-1}, Y=50 \%\right.$, $\mathrm{pH}=8$, and $\left.\theta=25^{\circ} \mathrm{C}\right)$.

both acting separately, but in an additive way on the transfer.

As illustrated in Table 2, $P_{s}$ values seemed to be highly dependent on the nature of anion of the electrolyte solute as well as on its concentration in solution.

The presence of strongly solvated anions $\left(\mathrm{SO}_{4}{ }^{2-}\right)$ in chromium solution leads to higher values of $P_{s}$ in comparison with the less solvated anions $\left(\mathrm{Cl}^{-}\right.$and $\left.\mathrm{NO}_{3}{ }^{-}\right)$ (Table 3). $P_{s}$ increased with salt concentration due to the high amount of hexavalent chromium passing through the membrane, while $\sigma$ decreased due to the reduction of salt retention [33]. The reflection coefficient $\sigma$ was higher in the presence of monovalent anions than bivalent anions. This may be due to the competition between chromium retention and the presence of anions. RO-SG membrane gives the highest values of reflection coefficient which were close to one, suggesting that the membrane gives nearly a complete rejection of hexavalent chromium and lower values of solute permeabilities compared to NF-HL membrane.

It was also noted that the diffusion part of flux was, in general, the highest in presence of $\mathrm{SO}_{4}{ }^{2-}$ which had the lowest diffusion coefficient as it increased with solute concentration. In addition, the convective contribution increased with solute 

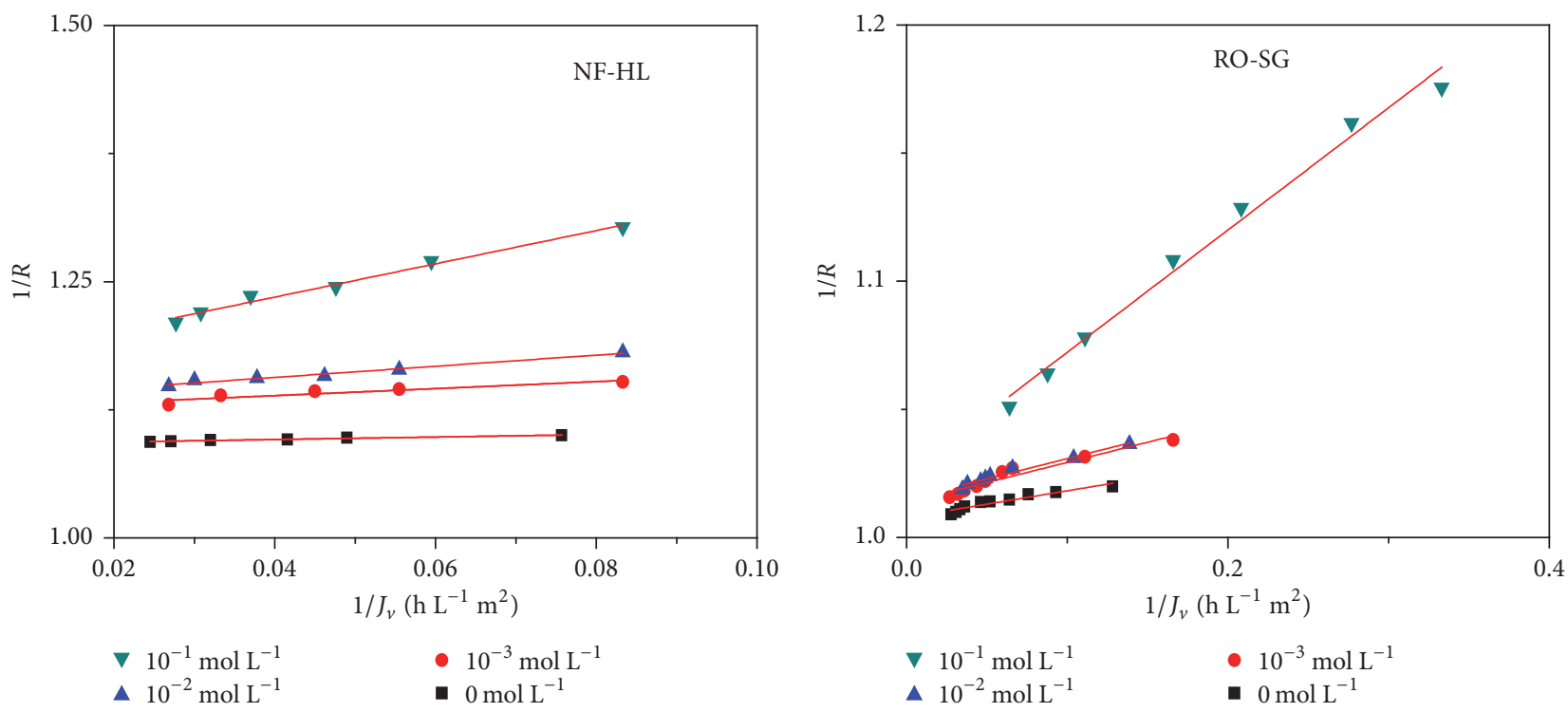

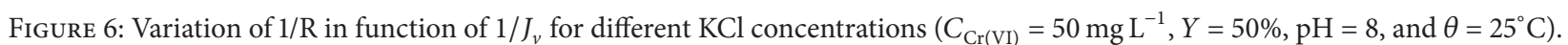

TABLE 2: Transport parameters $\left(\sigma\right.$ and $\left.P_{s}\right)$, diffusive flux $J_{\text {diff }}$ and $C_{\text {conv }}$ of hexavalent chromium in presence of different salts $\left(C_{\mathrm{Cr}(\mathrm{VI})}=\right.$ $50 \mathrm{mg} \mathrm{L}^{-1}, Y=50 \%, \mathrm{pH}=8$, and $\left.\theta=25^{\circ} \mathrm{C}\right)$.

\begin{tabular}{|c|c|c|c|c|c|c|c|c|c|c|}
\hline & & $\begin{array}{c}C \\
\left(\mathrm{~mol} \mathrm{~L}^{-1}\right)\end{array}$ & $\begin{array}{c}J_{\mathrm{diff}} \\
\left(\mathrm{Lh}^{-1} \mathrm{~m}^{-2}\right)\end{array}$ & $\begin{array}{l}\text { SD } \\
(\%)\end{array}$ & $\begin{array}{c}C_{\text {conv }} \\
\left(\mathrm{mg} \mathrm{L}^{-1}\right)\end{array}$ & $\begin{array}{l}\text { SD } \\
(\%)\end{array}$ & $\sigma$ & $\begin{array}{l}\text { SD } \\
(\%)\end{array}$ & $P_{s}$ & $\begin{array}{l}\mathrm{SD} \\
(\%)\end{array}$ \\
\hline \multirow{4}{*}{$\mathrm{KCl}$} & \multirow{4}{*}{ NF-HL } & 0 & 5.09 & 0.17 & 4.195 & 0.095 & 0.916 & 0.04 & 0.7102 & 1.06 \\
\hline & & 0.001 & 24 & 0.30 & 4.889 & 0.094 & 0.903 & 0.017 & 1.4879 & 3.68 \\
\hline & & 0.01 & 28.17 & 0.06 & 5.088 & 0.01 & 0.901 & $610^{-5}$ & 1.6384 & 2.65 \\
\hline & & 0.1 & 27.14 & 0.21 & 6.884 & 0.1 & 0.865 & $510^{-6}$ & 1.7517 & 4.75 \\
\hline \multirow{4}{*}{$\mathrm{KCl}$} & \multirow{4}{*}{ RO-SG } & 0 & 5.33 & 0.07 & 0.398 & 0.092 & 0.993 & 0.0095 & 0.168 & 0.06 \\
\hline & & 0.001 & 7.82 & 0.15 & 0.716 & 0.035 & 0.987 & 0.049 & 0.269 & 0.04 \\
\hline & & 0.01 & 7.80 & 0.01 & 0.801 & 0.01 & 0.985 & 0.1 & 0.267 & 1.09 \\
\hline & & 0.1 & 20.40 & 0.04 & 1.543 & $10^{-4}$ & 0.976 & 0.152 & 0.545 & 0.09 \\
\hline \multirow{4}{*}{$\mathrm{KNO}_{3}$} & \multirow{4}{*}{ NF-HL } & 0 & 5.09 & 0.09 & 4.195 & 0.004 & 0.916 & 0.38 & 0.7102 & 0.003 \\
\hline & & 0.001 & 11.97 & 0.02 & 5.715 & 0.0014 & 0.886 & 0.01 & 1.0366 & 0.09 \\
\hline & & 0.01 & 24.91 & 0.18 & 5.963 & 0.098 & 0.885 & 0.03 & 1.5274 & 1.63 \\
\hline & & 0.1 & 47.17 & 0.08 & 8.081 & 0.02 & 0.848 & 0.1 & 2.5262 & 0.08 \\
\hline \multirow{4}{*}{$\mathrm{KNO}_{3}$} & \multirow{4}{*}{ RO-SG } & 0 & 5.33 & 0.07 & 0.398 & 0.0003 & 0.993 & 0.03 & 0.168 & 0.007 \\
\hline & & 0.001 & 6.43 & 0.09 & 0.402 & 0.0007 & 0.992 & 0.04 & 0.184 & 0.0034 \\
\hline & & 0.01 & 8.43 & 0.04 & 0.509 & 0.0004 & 0.990 & 0.08 & 0.249 & 0.002 \\
\hline & & 0.1 & 12.52 & 0.03 & 1.739 & 0.0013 & 0.968 & 0.01 & 0.388 & 0.09 \\
\hline \multirow{4}{*}{$\mathrm{K}_{2} \mathrm{SO}_{4}$} & \multirow{4}{*}{ NF-HL } & 0 & 5.09 & 0.08 & 4.195 & 0.015 & 0.916 & $410^{-3}$ & 0.7102 & 0.008 \\
\hline & & 0.001 & 12.80 & 0.10 & 6.971 & 0.1 & 0.869 & 0.25 & 1.2333 & 0.001 \\
\hline & & 0.01 & 32.157 & 0.01 & 6.801 & 0.001 & 0.871 & 0.145 & 1.8242 & 0.001 \\
\hline & & 0.1 & 116.83 & 0.18 & 7.780 & 0.005 & nd & nd & nd & nd \\
\hline \multirow{4}{*}{$\mathrm{K}_{2} \mathrm{SO}_{4}$} & \multirow{4}{*}{ RO-SG } & 0 & 5.33 & 0.11 & 0.398 & 0.00023 & 0.993 & 0.049 & 0.168 & 1.78 \\
\hline & & 0.001 & 9.82 & 0.1 & 0.700 & $10^{-4}$ & 0.986 & 0.01 & 0.314 & 1.02 \\
\hline & & 0.01 & 8.24 & 0.2 & 0.884 & 0.0005 & 0.982 & 0.07 & 0.293 & 0.008 \\
\hline & & 0.1 & 21.77 & 0.2 & 2.746 & $1.1410^{-5}$ & 0.957 & 0.23 & 0.652 & 0.09 \\
\hline
\end{tabular}


TABLE 3: Hydration energies, hydrated radii, and diffusion coefficients of some ions [30, 31].

\begin{tabular}{|c|c|c|c|c|c|}
\hline Ion & $\mathrm{Na}^{+}$ & $\mathrm{K}^{+}$ & $\mathrm{Cl}^{-}$ & $\mathrm{NO}_{3}{ }^{-}$ & $\mathrm{SO}_{4}{ }^{2-}$ \\
\hline Hydration energies $\left(\mathrm{kJ} \mathrm{mol}^{-1}\right)$ & 454 & 363 & 325 & 310 & 1047 \\
\hline Hydrated radii (nm) & 0.358 & 0.331 & 0.332 & 0.335 & 0.379 \\
\hline$D\left(10^{9} \mathrm{~m}^{2} \cdot \mathrm{s}^{-1}\right)$ & 1.333 & 1.957 & 2.032 & 1.902 & 1.065 \\
\hline
\end{tabular}

TABLE 4: Water quality of car shock absorber factory before and after neutralization and comparison with Tunisian standards liquid discharges into the network "National Office for Sanitation" (ONAS) (NT 106-02).

\begin{tabular}{lccc}
\hline & $\begin{array}{c}\text { Wastewater } \\
\text { before neutralization }\end{array}$ & $\begin{array}{c}\text { Wastewater } \\
\text { after neutralization }\end{array}$ & $\begin{array}{c}\text { Tunisian standards } \\
(\text { NT 106-02) }\end{array}$ \\
\hline$T\left({ }^{\circ} \mathrm{C}\right)$ & 24 & 24 & $<35$ \\
$\mathrm{pH}$ & 13.45 & 8 & - \\
Conductivité $\left(\mu \mathrm{S} \mathrm{cm}^{-1}\right)$ & 3023 & 3027 & - \\
TDS $\left(\mathrm{mg} \mathrm{L}^{-1}\right)$ & 2293 & 2296 & - \\
Turbidité $(\mathrm{NTU})$ & 2.08 & 0 & - \\
$\mathrm{Cr}(\mathrm{VI})\left(\mathrm{mg} \mathrm{L}^{-1}\right)$ & 11.06 & 11.06 & 0.5 \\
\hline
\end{tabular}

concentration and it was higher with NF-HL than with ROSG membrane.

Even if the experimental rejection evolution with permeation flux was well-fitted by the model, in the case of bivalent salt $\mathrm{K}_{2} \mathrm{SO}_{4}$, the fit was not good; an inaccurate result was obtained $(\sigma>1)$.

\subsection{Removal of $\mathrm{Cr}(\mathrm{VI})$ from Car Shock Absorber Factory} Effluent. In this part, the efficiency of NF-HL and RO-SG membranes in reducing the amount of $\mathrm{Cr}(\mathrm{VI})$ ions from car shock absorber factory effluent was studied. Spiegler-Kedem model was applied to fit the experimental data and evaluate the parameters $\sigma$ and $P_{s}$. The optimal membrane was selected on several criteria such as water permeability, removal of total salinity, and hexavalent chromium selectivity.

Industrial effluent after neutralization with $\mathrm{HCl}$ was collected and analyzed. The results of feed water analysis are presented in Table 4.

3.2.1. Hydraulic Permeability of Wastewater. The experimental data for the permeate flux, with wastewater, as a function of the transmembrane pressure are given in Figure 7 for the two tested membranes.

The permeate fluxes obtained for the NF-HL membrane were higher than those of the RO-SG membrane. The wastewater permeabilities $\left(L_{p_{\text {NF-HL }}^{\prime}}^{\prime}=3.743 \mathrm{~L} \mathrm{~h}^{-1} \mathrm{~m}^{-2} \mathrm{bar}^{-1}, L_{p_{\mathrm{RO}-\mathrm{SG}}}^{\prime}=\right.$ $1.993 \mathrm{~L} \mathrm{~h}^{-1} \mathrm{~m}^{-2}$ bar $^{-1}$ ) were lower than those of pure water $\left(L_{p}\right)$. The presence of the electrolyte in solution made the membrane surface more compact due to the contraction of pores, resulting in a decrease in the permeability through membranes [34].

The critical pressure $P_{c}$ was defined as

$$
P_{c}=\sigma \cdot \Delta \pi \text {. }
$$

The critical pressure of RO-SG membrane ( $\mathrm{Pc}=$ 2.462 bar) was nearly two times higher than that of

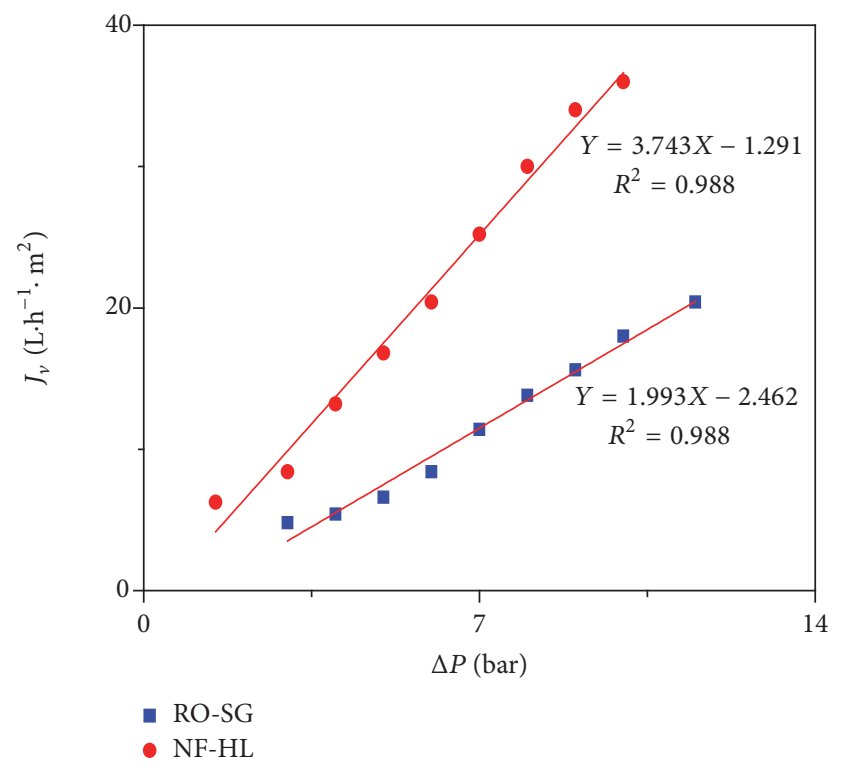

FIGURE 7: Effect of transmembrane pressure on the permeate flux of wastewater.

NF-HL membrane ( $\mathrm{Pc}=1.291$ bar) which was due to the higher rejection and the obviously higher osmotic pressure difference across the membrane. The NF-HL membrane having more open pores was less dependent on osmotic pressure compared with RO-SG membrane because of lower retentions.

3.2.2. Removal of Total Salinity. The highest retentions are obtained for RO-SG membrane (>90\%), while it was between 31.8 and $41.2 \%$ for NF-HL (Figure 8). There was an important effect of the screen phenomenon of the membrane charge at high concentration level, which was the case for the treated effluent. 
TABLE 5: Reflection coefficients $(\sigma)$ and solute permeabilities $\left(P_{s}\right)$ for total salinity and $\mathrm{Cr}(\mathrm{VI})$ ions of treated wastewater by NF-HL and RO-SG membranes.

\begin{tabular}{lccccc}
\hline Membrane & $C\left(\mathrm{mg} \mathrm{L}^{-1}\right)$ & $\sigma$ & SD (\%) & $P_{s}$ & 0,5356 \\
\multirow{2}{*}{ NF-HL } & $\mathrm{Cr}(\mathrm{VI})$ & 0.962 & 0.01 & 6,2616 & 0.09 \\
& Salinity & 0.443 & 1.04 & 0,2744 & 2.78 \\
\multirow{2}{*}{ RO-SG } & Cr(VI) & 0.985 & 0.03 & 0.07 & 0,5497 \\
& Salinity & 0.977 & 0.07 & 1.23 \\
\hline
\end{tabular}

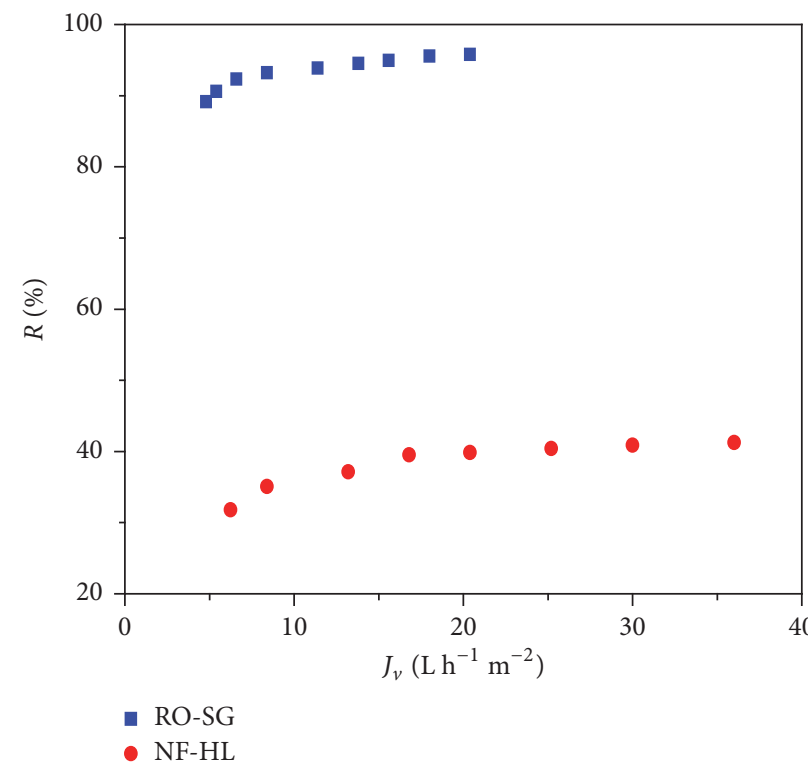

FIGURE 8: Total salinity rejection during wastewater treatment by NF-HL and RO-SG membranes, $\mathrm{pH}=8, Y=50 \%$, and $\theta=25^{\circ} \mathrm{C}$.

The permeate salinity confirmed the satisfactory performances of RO-SG $\left(249-97 \mu \mathrm{S} \mathrm{cm}^{-1}\right)$ for desalinating wastewater compared with NF-HL $\left(1565-1348 \mu \mathrm{S} \mathrm{cm}^{-1}\right)$.

3.2.3. Removal of Hexavalent Chromium. Experiments were conducted to determine the effectiveness of the two membranes for hexavalent chromium removal from wastewater and to possibly reuse the water.

The results showed that the two membranes were suitable for the treatment of the $\mathrm{Cr}(\mathrm{VI})$ present in the car shock absorber factory effluent (Figure 9).

The highest retentions are obtained for RO-SG membrane (94.5-97.7\%), while it was between 92.4 and $95.7 \%$ for NFHL. The permeate $\mathrm{Cr}(\mathrm{VI})$ concentration reached $0.47 \mathrm{mg} \mathrm{L}^{-1}$ for NF-HL and $0.24 \mathrm{mg} \mathrm{L}^{-1}$ for RO-SG. These values lied in the limits recommended by National Sanitation Utility of Tunisia (ONAS).

3.2.4. Modeling the Ion Rejection of Wastewater. SpieglerKedem model was applied to fit the rejection of total salinity and chromium ions. The fitting parameters $\left(\sigma\right.$ and $P_{s}$ ) for the two membranes are given in Table 5 .

$\sigma$ and $P_{s}$ values depended on the nature of the membrane. The RO-SG presented higher $\sigma$ values and lower salt permeabilities compared to the NF-HL membrane. The

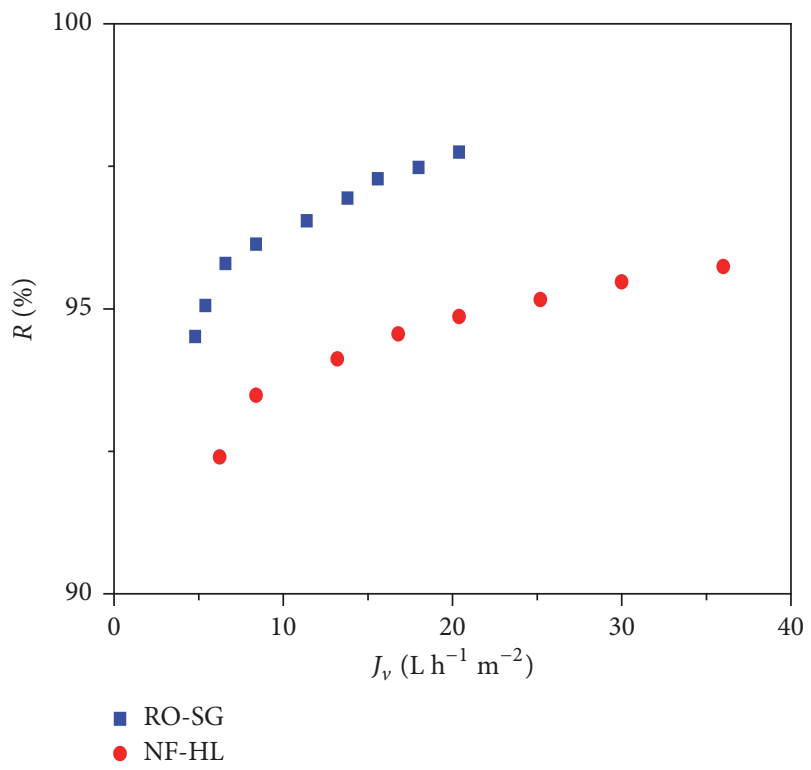

FIGURE 9: Retention rate of $\mathrm{Cr}(\mathrm{VI})$ versus transmembrane pressure for NF-HL and RO-SG membranes, $Y=50 \%, \mathrm{pH}=8$, and $\theta=25^{\circ} \mathrm{C}$.

reflection coefficient showed that the retention rate of $\mathrm{Cr}(\mathrm{VI})$ was higher than the total salinity. The model fitted well with the experimental data of the retention of both total salinity and hexavalent chromium ions for both membranes.

\section{Conclusion}

Hexavalent chromium removal was investigated using two commercial membranes (NF-HL and RO-SG). The removal efficiency for hexavalent chromium was influenced by ion concentration, $\mathrm{pH}$, conversion rate, transmembrane pressure, and the presence of different coexisting ions. The $\mathrm{Cr}(\mathrm{VI})$ retention of the RO-SG membrane was higher than that of NF-HL membrane under various operating conditions and reached the standard limits. It was observed that increasing ion concentration of the feed solution retention depended on $\mathrm{pH}$. The retention of chromium decreased with increasing concentration of the electrolyte support which might be explained as a result of decreasing effective charge density of the membrane surface. The reduction in membrane surface charge decreased the charge repulsion between the ions and the membrane. The experimental results showed that the use of these membranes was very promising for water treatment containing $\mathrm{Cr}(\mathrm{VI})$ with a good efficiency in desalting industry effluent. Membrane parameters (reflection coefficient and 
solute permeability) were shown to depend on the nature of membrane and the anions present in feed water.

\section{Conflicts of Interest}

The authors declare that they have no conflicts of interest.

\section{References}

[1] T. Voyslavov, S. Tsakovski, and S. Ganeva, "Determination of hexavalent chromium in aqueous and alkaline soil extracts," Turkish Journal of Chemistry, vol. 40, pp. 944-952, 2016.

[2] M. Costa and C. B. Klein, "Toxicity and carcinogenicity of chromium compounds in humans," Critical Reviews in Toxicology, vol. 36, no. 2, pp. 155-163, 2006.

[3] M. Pacheco, M. A. Santos, P. Pereira et al., "EPR detection of paramagnetic chromium in liver of fish (Anguilla anguilla) treated with dichromate(VI) and associated oxidative stress responses - Contribution to elucidation of toxicity mechanisms," Comparative Biochemistry and Physiology - Part C: Toxicology \&amp; Pharmacology, vol. 157, no. 2, pp. 132-140, 2013.

[4] M. E. Mahmoud, A. A. Yakout, A. M. Halbas, and M. M. Osman, "Remediation of $\mathrm{Cr}(\mathrm{VI})$ via combined self-reduction and adsorption bychemically modified carbon sorbents," Turkish Journal of Chemistry, vol. 40, no. 6, pp. 906-920, 2016.

[5] WHO, Guidelines for Drinking-Water Quality, World Health Organization, Geneva, Switzerland, 3rd edition, 2006.

[6] R. S. Bai and T. E. Abraham, "Biosorption of Cr (VI) from aqueous solution by Rhizopus nigricans," Bioresource Technology, vol. 79, no. 1, pp. 73-81, 2001.

[7] W. A. Smith, W. A. Apel, J. N. Petersen, and B. M. Peyton, "Effect of carbon and energy source on bacterial chromate reduction," Bioremediation Journal, vol. 6, no. 3, pp. 205-215, 2002.

[8] V. Neagu and S. Mikhalovsky, "Removal of hexavalent chromium by new quaternized crosslinked poly(4-vinylpyridines)," Journal of Hazardous Materials, vol. 183, no. 1-3, pp. 533-540, 2010.

[9] M. Bhattacharya, S. K. Dutta, J. Sikder, and M. K. Mandal, "Computational and experimental study of chromium (VI) removal in direct contact membrane distillation," Journal of Membrane Science, vol. 450, pp. 447-456, 2014.

[10] T. Z. Sadyrbaeva, "Removal of chromium(VI) from aqueous solutions using a novel hybrid liquid membrane-electrodialysis process," Chemical Engineering and Processing: Process Intensification, vol. 99, pp. 183-191, 2016.

[11] K. Mohammed and O. Sahu, "Bioadsorption and membrane technology for reduction and recovery of chromium from tannery industry wastewater," Environmental Technology and Innovation, vol. 4, pp. 150-158, 2015.

[12] W. Wang, M. Li, and Q. Zeng, "Adsorption of chromium (VI) by strong alkaline anion exchange fiber in a fixed-bed column: experiments and models fitting and evaluating," Separation and Purification Technology, vol. 149, no. 3, pp. 16-23, 2015.

[13] H.-J. Park and L. L. Tavlarides, "Adsorption of chromium(VI) from aqueous solutions using an imidazole functionalized adsorbent," Industrial and Engineering Chemistry Research, vol. 47, no. 10, pp. 3401-3409, 2008.
[14] I. Petrinic, J. Korenak, D. Povodnik, and C. Hélix-Nielsen, "A feasibility study of ultrafiltration/reverse osmosis (UF/RO)based wastewater treatment and reuse in the metal finishing industry," Journal of Cleaner Production, vol. 101, pp. 1-9, 2015.

[15] T. Bakalár, M. Búgel, and L. Gajdošová, "Heavy metal removal using reverse osmosis," Acta Montanistica Slovaca, vol. 14, no. 3, pp. 250-253, 2009.

[16] B. A. M. Al-Rashdi, D. J. Johnson, and N. Hilal, "Removal of heavy metal ions by nanofiltration," Desalination, vol. 315, no. 1, pp. 2-17, 2013.

[17] A. Mnif, M. B. S. Ali, and B. Hamrouni, "Effect of some physical and chemical parameters on fluoride removal by nanofiltration," Ionics, vol. 16, no. 3, pp. 245-253, 2010.

[18] M. Rai, G. Shahi, V. Meena et al., "Removal of hexavalent chromium Cr (VI) using activated carbon prepared from mango kernel activated with $\mathrm{H}_{3} \mathrm{PO}_{4}$," Resource-Efficient Technologies, vol. 2, pp. S63-S70, 2016.

[19] A. Mnif, D. Tabassi, M. Ben Sik Ali, and B. Hamrouni, "Phenol removal from water by AG reverse osmosis membrane," Environmental Progress and Sustainable Energy, vol. 34, no. 4, pp. 982-989, 2015.

[20] I. Bejaoui, A. Mnif, and B. Hamrouni, "Influence of operating conditions on the retention of fluoride from water by nanofiltration," Desalination and Water Treatment, vol. 29, no. 1-3, pp. 39-46, 2011.

[21] B. Tepuš, M. Simonič, and I. Petrinić, "Comparison between nitrate and pesticide removal from ground water using adsorbents and NF and RO membranes," Journal of Hazardous Materials, vol. 170, no. 2-3, pp. 1210-1217, 2009.

[22] A. Abouzaid, A. Mouzdahir, and M. Rumeau, "Study of the retention of monovalent and bivalent salts by nanofiltration," Comptes Rendus Chimie, vol. 6, no. 4, pp. 431-436, 2003.

[23] D. Tabassi, A. Mnif, and B. Hamrouni, "Influence of operating conditions on the retention of phenol in water by reverse osmosis SG membrane characterized using Speigler-Kedem model," Desalination and Water Treatment, vol. 52, no. 7-9, pp. 1792-1803, 2014.

[24] I. Bejaoui, A. Mnif, and B. Hamrouni, "Performance of Reverse Osmosis and Nanofiltration in the Removal of Fluoride from Model Water and Metal Packaging Industrial Effluent," Separation Science and Technology (Philadelphia), vol. 49, no. 8, pp. 1135-1145, 2014.

[25] L. K. Cabatingan, R. C. Agapay, J. L. L. Rakels, M. Ottens, and L. A. M. Van der Wielen, "Potential of biosorption for the recovery of chromate in industrial wastewaters," Industrial and Engineering Chemistry Research, vol. 40, no. 10, pp. 2302-2309, 2001.

[26] S.-S. Chen, B.-C. Hsu, C.-H. Ko, and P.-C. Chuang, "Recovery of chromate from spent plating solutions by two-stage nanofiltration processes," Desalination, vol. 229, no. 1-3, pp. 147-155, 2008.

[27] A. B. Nasr, C. Charcosset, R. B. Amar, and K. Walha, "Defluoridation of water by nanofiltration," Journal of Fluorine Chemistry, vol. 150, no. 1, pp. 92-97, 2013.

[28] A. Hafiane, D. Lemordant, and M. Dhahbi, "Removal of hexavalent chromium by nanofiltration," Desalination, vol. 130, no. 3, pp. 305-312, 2000.

[29] M. Muthukrishnan and B. K. Guha, "Effect of $\mathrm{pH}$ on rejection of hexavalent chromium by nanofiltration," Desalination, vol. 219, no. 1-3, pp. 171-178, 2008.

[30] E. R. Nightingale Jr., "Phenomenological theory of ion solvation. Effective radii of hydrated ions," Journal of Physical Chemistry, vol. 63, no. 9, pp. 1381-1387, 1959. 
[31] D.-X. Wang, M. Su, Z.-Y. Yu, X.-L. Wang, M. Ando, and T. Shintani, "Separation performance of a nanofiltration membrane influenced by species and concentration of ions," Desalination, vol. 175, no. 2, pp. 219-225, 2005.

[32] X.-L. Wang, T. Tsuru, S.-I. Nakao, and S. Kimura, "The electrostatic and steric-hindrance model for the transport of charged solutes through nanofiltration membranes," Journal of Membrane Science, vol. 135, no. 1, pp. 19-32, 1997.

[33] N. Hilal, H. Al-Zoubi, N. A. Darwish, A. W. Mohammad, and M. Abu Arabi, "A comprehensive review of nanofiltration membranes: Treatment, pretreatment, modelling, and atomic force microscopy," Desalination, vol. 170, no. 3, pp. 281-308, 2004.

[34] R. Huang, G. Chen, M. Sun, and C. Gao, "Preparation and characterization of quaterinized chitosan/poly(acrylonitrile) composite nanofiltration membrane from anhydride mixture cross-linking," Separation and Purification Technology, vol. 58, no. 3, pp. 393-399, 2008. 

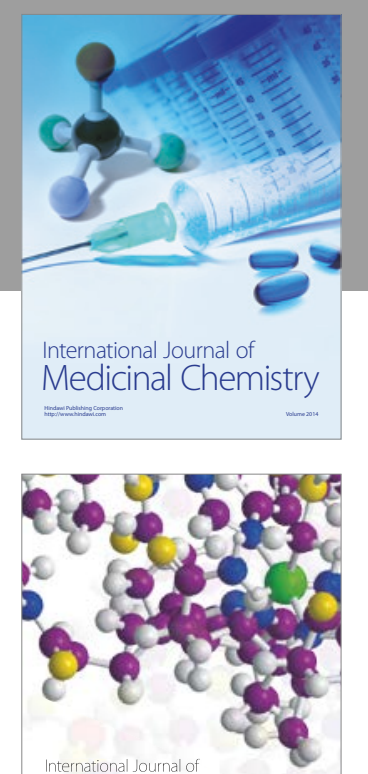

Carbohydrate Chemistry

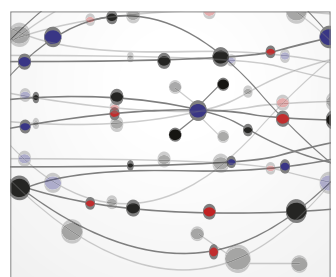

The Scientific World Journal
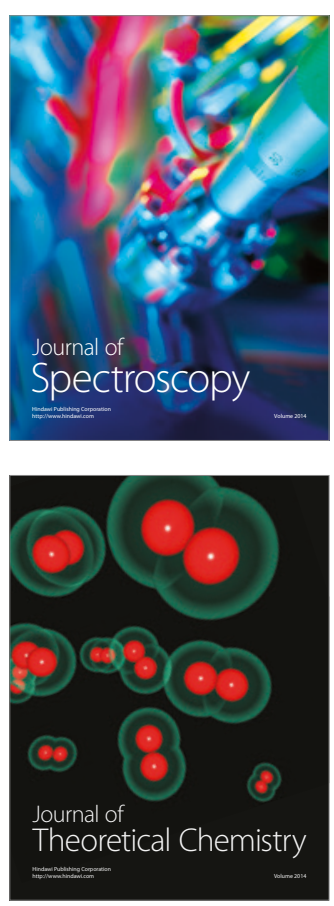
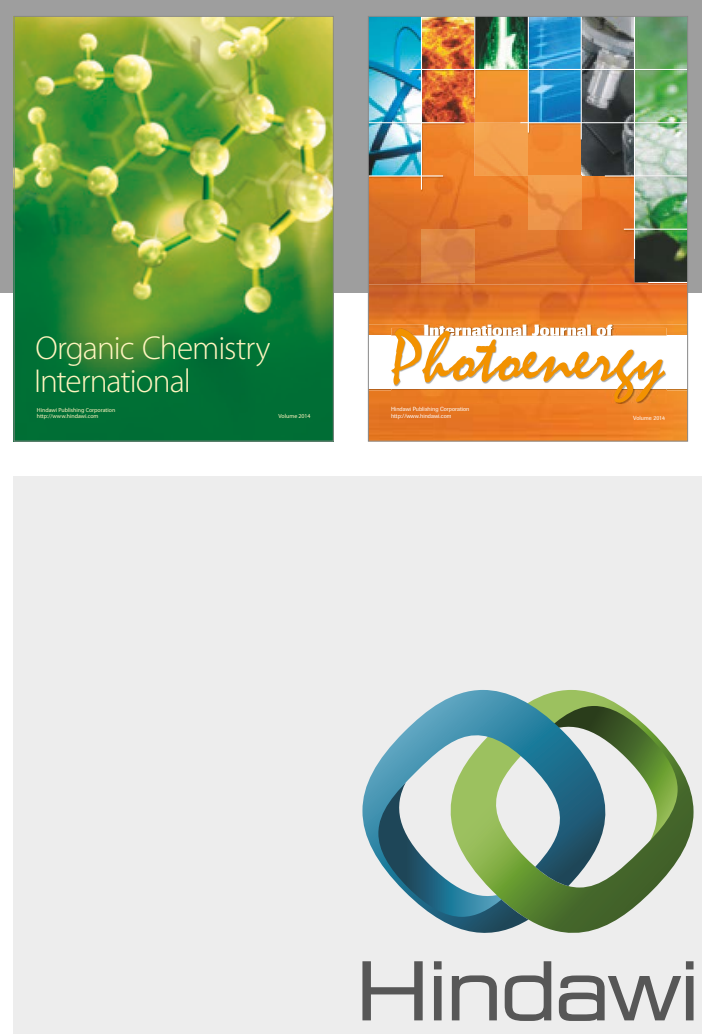

Submit your manuscripts at

https://www.hindawi.com

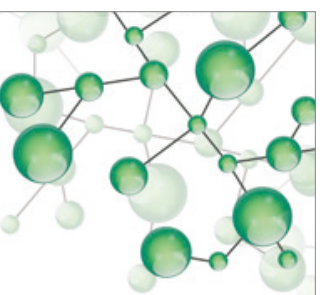

International Journal of

Inorganic Chemistry

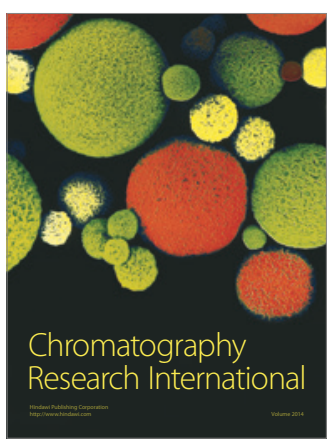

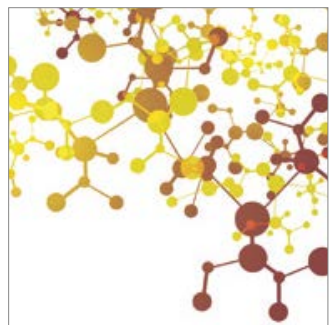

Applied Chemistry
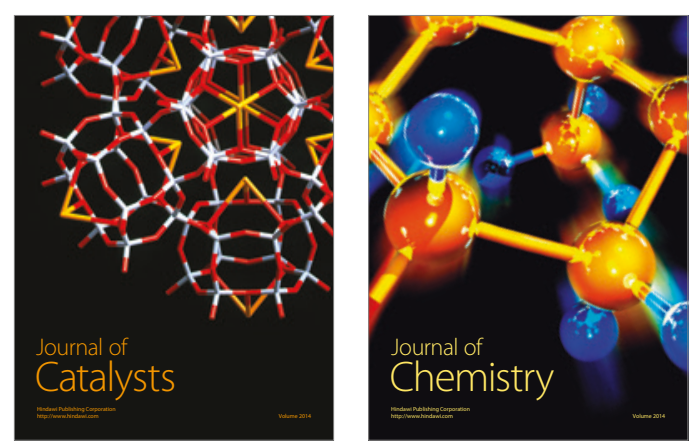
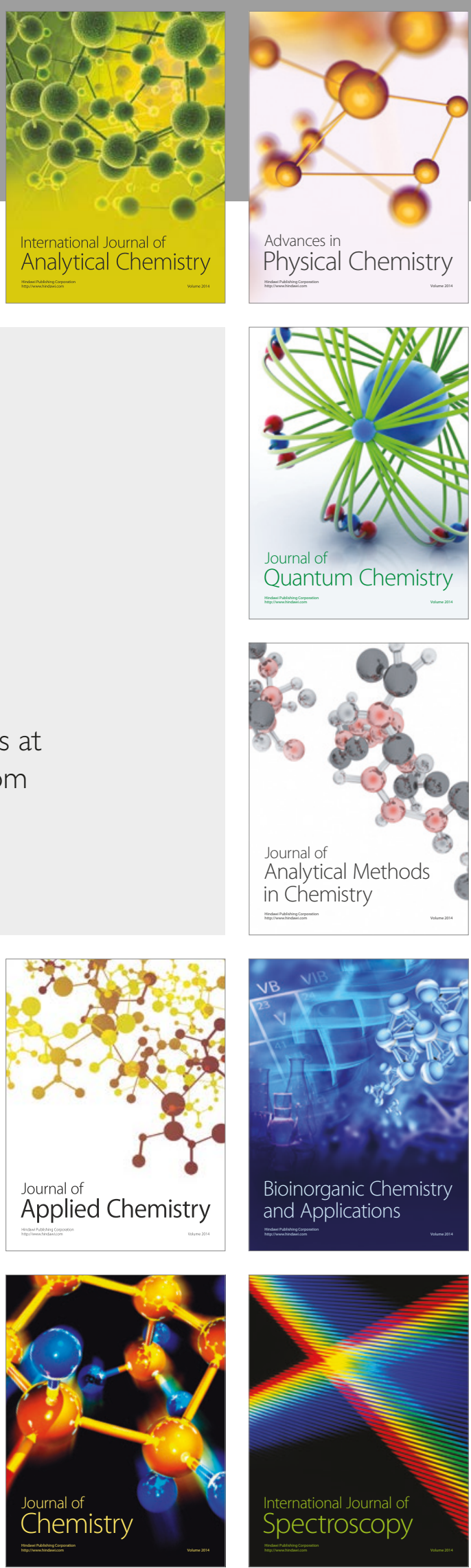